Pacific Northwest

National Laboratory

Operated by Battelle for the

U.S. Department of Energy

\section{DOE Advanced Controls R\&D Planning Workshop, June 11, 2003, Washington DC: Workshop Results}

\author{
MR Brambley \\ P Haves \\ SC McDonald \\ $P$ Torcellini
}

D Hansen

DR Holmberg

KW Roth

April 2005

Prepared for the U.S. Department of Energy under Contract DE-AC05-76RL01830 


\title{
DOE Advanced Controls R\&D Planning Workshop, June 11, 2003, Washington DC: Workshop Results
}

\author{
MR Brambley \\ D Hansen \\ P Haves \\ DR Holmberg \\ SC McDonald \\ KW Roth \\ P Torcellini
}

April 2005

Prepared for the U.S. Department of Energy under Contract DE-AC05-76RL01830 


\title{
DISCLAIMER
}

This report was prepared as an account of work sponsored by an agency of the United States Government. Neither the United States Government nor any agency thereof, nor Battelle Memorial Institute, nor any of their employees, makes any warranty, express or implied, or assumes any legal liability or responsibility for the accuracy, completeness, or usefulness of any information, apparatus, product, or process disclosed, or represents that its use would not infringe privately owned rights. Reference herein to any specific commercial product, process, or service by trade name, trademark, manufacturer, or otherwise does not necessarily constitute or imply its endorsement, recommendation, or favoring by the United States Government or any agency thereof, or Battelle Memorial Institute. The views and opinions of authors expressed herein do not necessarily state or reflect those of the United States Government or any agency thereof.

\author{
PACIFIC NORTHWEST NATIONAL LABORATORY \\ operated by \\ BATTELLE \\ for the \\ UNITED STATES DEPARTMENT OF ENERGY \\ under Contract DE-AC05-76RL01830
}

Printed in the United States of America
Available to DOE and DOE contractors from the Office of Scientific and Technical Information,
P.O. Box 62, Oak Ridge, TN 37831-0062;
ph: (865) 576-8401
fax: (865) 576-5728
email: reports@adonis.osti.gov

\author{
Available to the public from the National Technical Information Service, \\ U.S. Department of Commerce, 5285 Port Royal Rd., Springfield, VA 22161 \\ ph: (800) 553-6847 \\ fax: (703) 605-6900 \\ email: orders@ntis.fedworld.gov \\ online ordering: http://www.ntis.gov/ordering.htm
}




\title{
DOE Advanced Controls R\&D Planning Workshop, June 11, 2003, Washington DC: Workshop Results
}

\author{
MR Brambley ${ }^{(a)}$ \\ D Hansen $^{(\mathrm{b})}$ \\ P Haves ${ }^{(\mathrm{c})}$ \\ DR Holmberg ${ }^{(\mathrm{d})}$ \\ SC McDonald ${ }^{(a)}$ \\ KW Roth ${ }^{(f)}$ \\ P Torcellini ${ }^{(e)}$
}

April 2005

Prepared for

the U.S. Department of Energy

under Contract DE-AC05-76RL01830

Pacific Northwest National Laboratory

Richland, Washington 99352

\footnotetext{
(a) Pacific Northwest National Laboratory

(b) U.S. Department of Energy

(c) Lawrence Berkeley National Laboratory

(d) National Institute of Science and Technology

(e) National Renewable Energy Laboratory

(f) TIAX, LLC
} 



\section{PREFACE}

The Building Technologies Program (BT) is one of 11 programs within the Office of Energy Efficiency and Renewable Energy (EE) at the U.S. Department of Energy (DOE). The mission of the Building Technologies Program is to develop technologies, techniques and tools for making residential and commercial buildings more energy efficient, productive, and affordable. The Building Technologies Program's goal is to develop cost effective tools, techniques and integrated technologies, systems and designs for buildings that generate and use energy so efficiently that buildings are capable of generating as much energy as they consume. One subprogram within BT is Commercial Building Integration. The Commercial Buildings Integration subprogram addresses energy saving opportunities in new and existing commercial buildings. This includes research, development, and demonstration of whole building technologies, design methods, and operational practices. Technology development efforts focus on cross-cutting, whole building technologies such as sensors and controls and more energy-efficient ventilation systems. This also includes efforts to improve commercial building energy codes and standards. These efforts support the net Zero Energy Buildings goal not only by reducing building energy needs, but also by developing design methods and operating strategies that seamlessly incorporate solar and other renewable technologies into commercial buildings.

The Commercial Building Integration sub-program is in the process of developing a five-year research and development plan for advanced control technologies for building applications. The goal of the planning process is to identify opportunities for targeted $R \& D$ that will result in significantly increased use of control technologies with a goal of saving energy. As a first step toward the development of a plan, DOE prepared background material to:

- Assess the current market and technical potential

- Analyze current and potential applications

- Investigate potential improvements to sensors and controls

- Identify efforts required in networks including standards and protocols

- Examine enhancements to applications of strategies such as commissioning, performance monitoring, and diagnostics.

The second step was to seek outside review and input into the planning process from technical and market experts from universities, other government agencies, and the private sector. These experts were invited to a one-day workshop in Washington, DC, on June 11, 2003. The workshop participants were given the opportunity to review the background planning material, listen to summary presentations of the results, and provide comments on the findings. The workshop participants also participated in breakout sessions where R\&D opportunities were prioritized and refined.

The final step in the process is for DOE to use the input gathered during this planning process to develop a formal five-year plan. DOE will need to select from among the R\&D opportunities 
based on internally developed criteria. In some cases, additional analysis may be required to define the resource requirements as well as the prospective market impacts of suggested R\&D pathways. DOE will continue to seek comment and input from outside parties as it works to refine this plan. 


\section{SUMMARY}

On June 11, 2003, representatives from universities, federal, and state government agencies, U.S. Department of Energy (DOE) national laboratories, and the private sector attended a one-day workshop in Washington, DC. The objective of the workshop was to obtain review and input of DOE's assessment of the market for advanced controls technology and potential R\&D pathways to enhance the success of advanced controls in the buildings market place. Attendees were provided with a draft synthesis paper summarizing the market assessment and potential R\&D pathways. ${ }^{1}$ This background material was developed with the help of several DOE national laboratories, the National Institute of Standards and Technology, and private-sector consultants.

The workshop consisted of two sessions. During the morning session, participants were given an overview on each topic area in the synthesis paper (e.g., market analysis). This included an opportunity for comments and questions by participants. Some of the key observations were as follows:

\section{- $\quad$ Market Assessment}

o Building control systems are often not purchased for their potential energy savings, but rather for reducing maintenance and other reasons.

o Several existing controls approaches have the technical potential to reduce U.S. commercial building energy consumption by at least one quad per year.

o Control systems are one of the last items considered during the design and construction process, which leads to lower-cost controls implementations.

o In the predominant construction paradigms, contractors tend to re-use structural elements from building to building (with some site-related variation) and design work is often formula and rule-of-thumb driven. This works against the use of advanced controls approaches.

o Building owners typically pay little attention to energy expenditures and savings potential because building energy expenses account for a diminutive fraction of total building economic activity (e.g., $1 \%$ of total office expenses).

o Operators have a difficult time understanding current systems, let alone advanced systems.

o Currently, most advanced controls approaches have a very small market share.

o The ability of building controls to provide non-energy benefits to building owners and occupants holds the key to greater future market penetration and national energy

\footnotetext{
1 "Advanced Sensors and Controls for Building Applications: Market Assessment and Potential R\&D Pathways,” Synthesis Report, DRAFT, June 2003 (formerly titled Advanced Sensors and Controls R\&D Plan for Building Applications).
} 
savings. Building controls that improve indoor environmental quality (IEQ) can greatly improve their value to the building occupants, primarily by increasing the economic activity in the building, e.g., office worker productivity or retail sales. For instance, roughly a $2 \%$ increase in the productivity of office building occupants has the same economic impact as eliminating all building operations and energy expenditures - employee salaries simply account for a much, much larger portion of total building expenses. The market potential might be greater if $\mathrm{R} \& \mathrm{D}$ results in systems that are cheaper, easier to use, or have the functionality that consumers want (the current market assessment only deals with current technology).

- Current Applications and Strategies for New Applications

o New functionality (e.g., demand response) increases market potential, but also adds complexity which may ultimately limit the market for these products.

o DOE should develop a succinct vision of what control strategies could mean for building operation (e.g., disaster mitigation) rather than defining control strategies as a response to current needs.

- $\quad$ Sensors and Controls

o While it is possible to develop sensors for a host of applications (e.g., mold detection, VOCs, $\mathrm{CO}^{2}$ ), the market for these types of sensors may not develop. The ability to monitor these contaminants implies a requirement to respond and may carry liability that building owners and operators are unwilling to assume.

o There is a good deal of experience in other industries with sensors and control processes from which this program might benefit (e.g., Predictive Maintenance, as practiced in the nuclear industry).

o A missing element is the human interface; how all this data is to be presented, interpreted, and acted upon.

- Networking, Security, and Protocols and Standards

o Networks need to be self-configuring and self-healing as there will simply not be enough network engineers to satisfy future demand for services.

o Communication is not just an issue of inter-control and interoperability but also of the ability to share data.

- Automated Diagnostics, Performance Measurement, Commissioning, and Optimal Control, and Tools

o Automated diagnostics can be applied at three levels: the component level, the subsystem level, and the whole building level. Most of the R\&D performed to date has been at the component and subsystem levels. The market analysis primarily deals with building-level systems.

o More "commissioning" may be taking place in-house than is generally recognized as progressive maintenance staff perform these functions. 
The afternoon consisted of breakout sessions on each R\&D option area.

The workshop participants were asked to review the potential R\&D pathways, identify highpriority activities, and outline a five-year path for each of these activities. The prioritization was based on project selection criteria developed by DOE:

- largest and quickest impact

- best use of finite resources

- greatest likelihood for market penetration

- $\quad$ ability to replicate results.

In addition, the participants were asked to identify DOE's role vis-à-vis other participants. The most promising R\&D opportunities identified by the workshop participants were as follows: ${ }^{2}$

- Current Applications and Strategies for New Applications

o Next-generation user and automatic controls for lighting and HVAC systems

o Tools to simulate subsystem and building-level system controls (including utility interface)

o Optimization of existing systems

o Dynamic envelope control integration (lighting, thermal ventilation, chemical/bio filter)

- $\quad$ Sensors and Controls

o Communication: wired vs. wireless (lower cost, powering)

o Advanced sensors (volumetric air-flow, VOCs, etc.)

o Testing and qualifying sensors, control systems, and human interfaces

o Self-calibrating sensors

- Networking, Security, and Protocols and Standards

o Information and security needs for protocols for new technologies and services

o Utility-networking requirements

o Ability to integrate existing component protocols into an advanced whole building master control system.

\footnotetext{
${ }^{2}$ A breakout session was not held for the Market Assessment. DOE is funding a follow on, more detailed Market Assessment, which will in part be shaped by input from the workshop participants.
} 
- Automated Diagnostics, Performance Measurement, Commissioning and Optimal Control and Tools

o Performance monitoring data management, analytical tools, and optimal sensor placement

o Automated fault detection and diagnosis

o Commissioning crosscutting test methods

o Tools testing and evaluation (using simulation and active crosscutting tests). 


\section{CONTENTS}

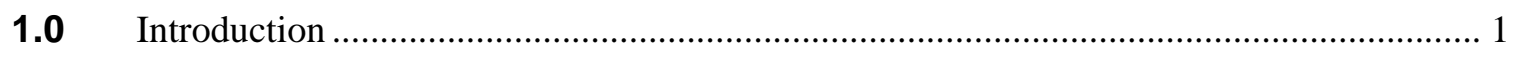

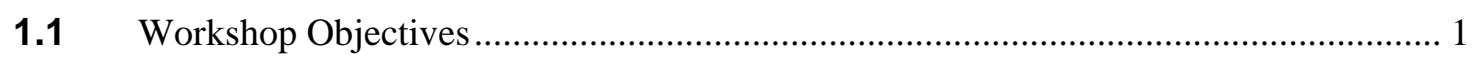

1.2 DOE Project Selection Criteria .............................................................................. 1

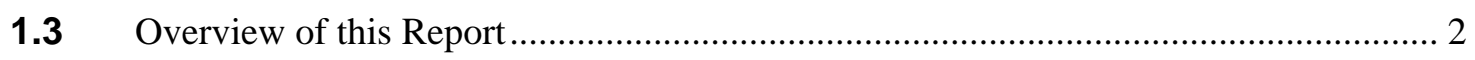

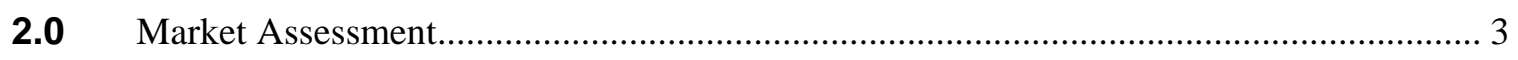

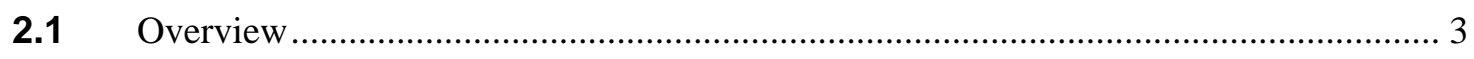

$2.2 \quad$ Workshop Results ..................................................................................... 4

3.0 Current Applications and Strategies for New Applications ............................................. 5

3.1 Overview ............................................................................................. 5

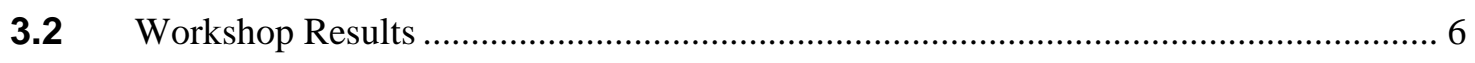

4.0 Sensors and Controls .................................................................................... 9

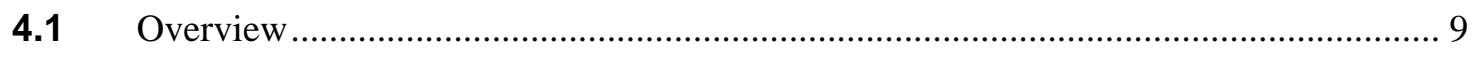

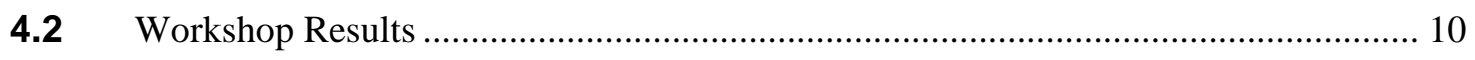

5.0 Networking, Security, and Protocols and Standards .................................................. 13

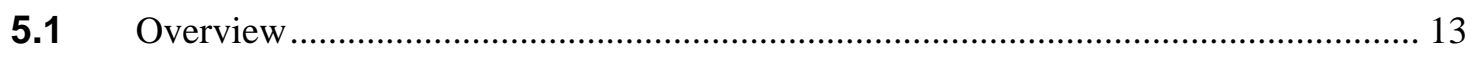

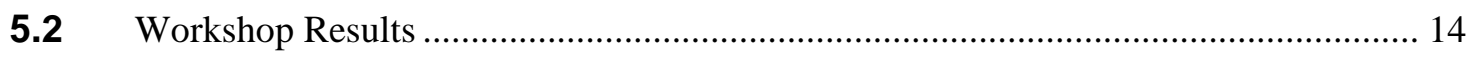

6.0 Automated Diagnostics, Performance Measurement, Commissioning and Optimal Control and Tools........................................................................................ 15

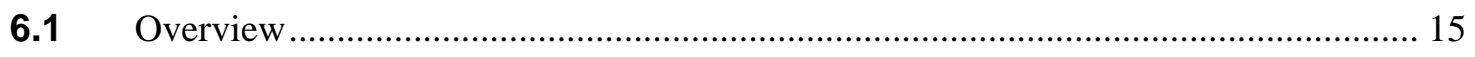

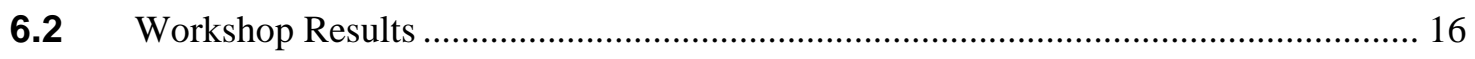

Appendix A - Workshop Agenda …………………………………………………….... 19

Appendix B - Workshop Attendees.................................................................................. 23

Appendix C - R\&D Workshops ……………………………………………………... 29 


\subsection{INTRODUCTION}

One of the strategies identified in DOE's High-Performance Commercial Buildings ${ }^{3}$ Roadmap is to

"Develop systems integration, monitoring, and other technologies that enable commercial buildings to optimally achieve targeted performance levels over their life cycles."

The challenge includes the optimization of system interactions (e.g., windows, lights, and heating and cooling systems) despite the fact that most buildings are relatively "dumb" in their operation. The roadmap points the way but is silent as to how to get there. The goal of the Advanced Sensors and Controls R\&D plan is to develop a pathway to achieve these advances with some specificity as to what needs to be accomplished in the next five years.

On June 11, 2003, representatives from universities, federal and state government agencies, U.S. Department of Energy national laboratories, and the private sector attended a one-day workshop in Washington, DC. In preparation for the workshop, attendees were provided with a draft synthesis paper summarizing the market assessment and potential R\&D pathways. ${ }^{1}$

\subsection{Workshop Objectives}

The objective of the workshop was to review and provide input into DOE's assessment of the market for advanced sensors and controls technology and potential R\&D pathways to enhance their success in the buildings marketplace. Through this workshop, DOE sought input and validation on both the market assessment and R\&D pathways contained in the background synthesis paper. ${ }^{4}$ DOE also wanted stakeholder input on the proper path forward, given the choices and the current understanding of the market, for a research program in advanced controls and sensors. In short, the strategy was to validate the needs (market assessment), develop R\&D options to address these needs (pathways), and formulate a five-year R\&D plan based on prioritized options.

\subsection{DOE Project Selection Criteria}

DOE has a set of project selection criteria. The first of these is to have a large and relatively near- to mid-term impact on both new and existing commercial buildings. The market assessment identifies the magnitude of current technology, but not potential future technology. The goal is to reduce overall source energy use, but peak demand is also a concern.

\footnotetext{
3 "High-Performance Commercial Buildings High-Performance Commercial Buildings: A Technology Roadmap,” US Department of Energy, October 2000.

${ }^{4}$ Advanced Sensors and Controls for Building Applications: Market Assessment and Potential R\&D Pathways,” DRAFT, June 2003.
} 
Second, DOE wants to be certain it is making the best use of finite resources. As such, the fiveyear plan should identify not only the options, but also the need for collaborations with others and synergies (including dependencies) with other related technologies. DOE recognizes there is substantial research and development taking place in industry and by other government agencies.

Third, technologies should have attributes that will increase the probability of substantial market penetration. Energy savings alone, while a primary objective for DOE, is probably not enough of a motivating factor to achieve the full market potential. The cost of the technology and ease of use, as well as other attributes that increase market acceptance, are important.

Finally, the ability to replicate results is essential. Technologies and applications should be broad based and applicable to a variety of building types and uses. Technologies that require substantial modification or tuning for each installation will not find a broad application.

\subsection{Overview of this Report}

Workshop participants were given overviews on the five topic areas in the synthesis paper:

- market assessment

- current applications

- $\quad$ sensors \& controls

- networking security

- $\quad$ automated diagnostics.

Summaries of those overviews are provided in Chapters 2 through 6 below, along with results of discussions by workshop participants.

Appendix A of this report is the workshop agenda, Appendix B lists workshop attendees and their contact information, and Appendix $\mathrm{C}$ contains worksheets from the breakout groups. These worksheets were provided to DOE to assist in developing a prioritized multi-year plan. 


\subsection{MARKet AsSessment}

\subsection{Overview}

The goal of the market assessment is to identify the opportunities for building controls. In summary, the goal is to identify current control technologies and the extent of their use and to understand their energy saving potential. The market assessment also discusses barriers to building controls, as well as value propositions that can increase their likelihood of market adoption.

In 2002, the commercial buildings sector consumed 17.4 quadrillion Btus (Quads) of primary energy (including electricity generation losses), out of total U.S. annual consumption of about 100 quads. Heating, ventilation, and air conditioning (HVAC) and lighting account for about $32 \%$ and $25 \%$, respectively, of primary commercial-sector energy consumption. ${ }^{5}$ In addition, the "internal gains" from the heat generated in lighting is the principal contributor to building cooling loads. ${ }^{6}$ This means that one strategy for reducing peak electric demands in cooling is better use and control of lighting.

The total U.S. sales of building controls (including equipment, and installation and services) equal about $\$ 3$ billion per year. Existing buildings account for about $75 \%$ of this market. Therefore, the retrofit market is a primary target of this endeavor.

Installation and commissioning accounts for more than 70\% of Direct Digital Controls (DDC) building control system installed costs. As such, reductions in installation costs are very valuable. The cost to maintain the system is also significant.

In general, the market penetration of building controls has a negative correlation with the degree of sophistication. Penetration also varies with building size, i.e., smaller buildings have much fewer central control systems. Even though many central systems have very sophisticated functionality, users often do not take advantage of this functionality. Existing systems mainly serve building plant functions.

Data limitations make it difficult to quantify the market-achievable energy savings potential from alternative control approaches. The economics tend to be case-specific and, therefore, make extrapolation to develop a national energy saving potential very problematic. Most approaches appear to have a theoretical energy saving potential of at least 0.5 quads (assuming full market penetration), but the controls approaches studied typically have a large estimated payback period and energy savings ranges.

\footnotetext{
${ }^{5}$ Buildings Core Databook, 2004, Table 1.3.3 (http://buildingsdatabook.eere.energy.gov/docs/1.3.3.pdf)

6 "Commercial Heating and Cooling Loads Component Analysis," Lawrence Berkeley National

Laboratory, June 1998, Table 24, p. 45 and Figure 3, p. 61.
} 
Building owners often do not purchase control systems for their energy savings potential but to reduce maintenance expenses and for other reasons. A 2 to 4-year payback is typically required to interest the building operator in an Energy Management and Control System (EMCS). Control systems are usually considered rather late in the design and construction process, which limits the funds available for controls and the ability to consider more sophisticated controls.

The current market analysis broadly frames the opportunities for future R\&D to increase the market share of building controls, be it through measures that reduce the installed cost of building controls or that provide meaningful non-energy benefits to building owners. What can R\&D do to increase the amount of savings possible from the building stock?

- Enhance the Indoor Environment -Focus on measures that do more than save energy, most notably that enhance the productivity of the core economic activity of the building. Building economic activity (salaries, sales) accounts for a much greater portion of total building expenditures than energy.

- $\quad$ Reduce Installed Cost - Installation accounts for a significant part of the cost of new control systems. Lower installed cost reduces owners' concerns about first cost, increasing the likelihood that owners will invest in building controls.

- $\quad$ Reduce Building Controls O\&M Costs - lowering both system cost as well as general maintenance cost in the building through automation and early detection.

Overall, productivity gains have the potential to be a much more potent value proposition for building controls than energy savings. These goals can be complementary, but research aimed solely at reducing energy does not address this most potent market driver. A fundamental change is required in the way buildings are operated, both from a technical and business perspective, in order to realize the full potential, including energy savings, from advanced controls systems.

\subsection{Workshop Results}

The workshop participants generally agreed that a follow-on market assessment was needed. What has not been explored in the initial study is the potential energy savings from more advanced technologies that would result from research and development. This type of analysis requires postulating the future cost and performance of advanced technologies that might be developed as a result of R\&D. DOE has initiated this follow-on analysis with TIAX, LLC, which will be available in midyear in 2005.

The current market assessment focused on the market-achievable energy savings from existing technologies. There remains a great deal of uncertainty (sometimes as much as an order of magnitude) about what this potential is. This uncertainty primarily results from large ranges in economic attractiveness and, hence, the projected market penetration of the technologies. 


\subsection{CURRENT APPliCATIONS AND STRATEgiES FOR NEW APPLICATIONS}

\subsection{Overview}

There is already substantial market experience with existing Energy Management and Controls Systems (EMCS). Better information is needed on current savings from current technologies and applications as we look to new applications. Better understanding is needed as to how current systems are being used, and to what degree, and what features or attributes are needed to improve existing performance.

System complexity remains an issue. Current systems are not reaching their full potential as users do not understand how to take advantage of advanced features. Once again this must be addressed to move forward into new applications and strategies.

New HVAC controls are not really improving on control algorithms. For the most part, they are limited to a single input and single output control. The human interface to these control systems also needs to be addressed as well as optimization for the entire building.

For lighting controls a host of issues arise. For instance, how do we bind the appropriate switch to the appropriate sensor? Daylighting is one of the biggest potentials for energy savings, but lighting quality control becomes difficult with daylighting. Finally, as lighting is a significant energy use, and also is a major contributor to the building's cooling load, ${ }^{7}$ and in some sense variable, we need to be able to respond to utility control measures and still provide a quality working environment.

Present-day systems tend to be customized and wire-based. As a result, they are expensive, hard to maintain, and take significant effort to install and program. One of the challenge areas is to reduce these installation costs by developing systems that are more "self-learning," that reduce their costs of implementation. (i.e., "plug \& play" in the computer industry).

Disaster minimization and mitigation is a potential new application area for building control systems (BCS). What are the potential building responses to an emergency situation? Is it possible to run building systems at different levels of operation and how do we control for this?

Demand response to changing electricity prices will require some sort of BCS. How should buildings respond (and to what degree) to real-time pricing of electricity? There is no real understanding of how this information and response mechanism would operate in a BCS. Current controls systems and existing models for designing buildings do not take this into account. There

\footnotetext{
7 “Commercial Heating and Cooling Loads Component Analysis,” Lawrence Berkeley National Laboratory, June 1998, Table 24, p. 45 and Figure 3, p. 61.
} 
is no real global look at how to shift demand in the building. The usual response is just cycling air handlers on a ten-minute schedule or other simple strategies.

Optimization of energy use can be incorporated both into design and into operation. Current design tools are good at certain things, but do not necessarily look at demand response and other factors. On the operation side, it is unclear that the BCSs that are being installed now actually have the capability for optimization.

Since experiments with real buildings are costly, good models for building simulation are essential. You cannot develop design tools or BCSs without good underlying simulations. Many of the models used are not based on physics, but on empirical models.

There has been substantial discussion about natural ventilation. However, fire protection issues and other barriers limit the implementation of $100 \%$ naturally ventilated building designs. Thus we build hybrid systems. There is a potential market for BCS in managing these hybrid systems.

This is a natural tension between additional complexity and increased applications. For example, demand response is seen as useful and a potential market. However, forethought must be given as to what the desired outcome and features should be. DOE could assist this process by providing a more succinct vision of how a building should operate and hence the role of controls.

\subsection{Workshop Results}

The next generation of user and automatic controls is needed. Two target systems were identified. These are

- lighting

- retrofit air conditioning (for buildings currently without A/C).

A "skunkworks" approach could be used to help industry define the next generation of lighting technologies. There would be parallel efforts in HVAC. These teams would work with a clean slate to develop new approaches.

A second area is tools and simulation. It is important to develop tools that could be used in the design phase, and then later in the commissioning and operating phases of the building. Tool development could start with a simplified version just to address lighting and HVAC. Other EMCS-like capability could be added in later years. Lab and field testing of the software against real data would be a longer term process. There is also a need to develop guidance in making simulation input assumptions during the design process.

A third area is optimization of existing systems. This would start with measurements of buildings that were designed using simulation tools. Predicted energy use would be measured against actual energy use. The idea would be to examine the use of tools to assess potential and to determine the viability and need for real-time optimization. 
Finally, there is a need for the integration of all sensors and controls systems into a "Dynamic Envelope Control Integration System” or "Whole Building” control system. This would begin with an analysis of the requirements for the next generation of building control systems to handle not only traditional lighting and HVAC, but also building envelope interactions. An assessment would be made of the kinds of control strategies that are needed to link these subsystems. Included in this are issues of optimization in the context of real-time pricing and on-site generation. 


\subsection{SENSORS AND CONTROLS}

\subsection{Overview}

A process cannot be controlled if it cannot be measured (or sensed). But in order to increase the use of sensors, costs need to be lower and reliability and performance improved. Sensors need to measure parameters we might not be measuring today. For instance, most sensors do not measure real occupancy, just motion.

New sensors (or broader application of novel sensors) may allow us to meet novel or emerging human needs (e.g., CO2 and mold growth). However, these new sensors also present problems for building owners. The ability to measure also implies the ability to act to prevent or redress a problem. It also implies a standard against which contaminant levels are being measured (where none may exist).

If wireless sensors are seen as offering significant potential, especially for retrofits, the question arises as to how these will be powered. Low-cost batteries are one possibility, but battery replacement causes a maintenance issue and a disposal issue. A potential area of research is energy scavenging from vibration and other sources.

An identified gap is sensor system testing and qualification. How do we ensure that sensors operate in the field the same way they did in the laboratory and in both natural and human-created environments? There is also a need for testing to uncover problems that can occur with vandalism and other potential damage as well as long-term calibration issues.

On the controls side, there is a need for controls that provide smoother transitions when switching modes. Sometimes controllers fail to switch operating modes between seasons or during unusual weather occurrences. Fault tolerant controls are needed when there are faulty sensors. Controls also need to have predictive capabilities to have the ability to minimize peak demand.

Hybrid controls are systems that combine state machines and continuous controllers. There are opportunities for this industry to learn from other industries such as automotive and aerospace and to bring that knowledge to buildings. The question is: "What is the DOE role in bringing these sorts of hybrid controls to the building marketplace?"

Cost-effective methods are needed to retrofit controls. This will broaden the market to existing buildings and make upgrades possible.

The interaction of sensors and controls is important. Guidelines are needed for installation and selection in order to properly match sensors and controls. Ensuring good performance even under conditions of sensor failure is another need. 
Actuators perform the mechanical task of opening and closing dampers and other physical operations. There is a need to improve the reliability, life and performance of actuators. There is a trade-off between optimal dynamic response and robustness. Control that is not robust can result in oscillatory behavior (hunting for the exact right setting). This can cause premature failure of the actuators.

An important area for research is the human-control system interaction. The need is to convey information, not data, and ideally to alert to problems and suggest remedies. Until the human interface is understood, systems will continue to operate well below their optimal level. System interfaces not only are for the building operator, but a level of system interface is needed for the building users.

In terms of actuator operation, there is a need to look at building operation in a totally new way. If cars were operated similar to commercial buildings, we would run the engine and transmission at maximum throttle and only use the brake to control the vehicle. We need to make controls that will maintain building operations with minimum expenditures of energy.

\subsection{Workshop Results}

The approach was to take initial ideas for R\&D topics and categorize them. Two new sections were identified as part of this process. The group established priorities, ranked the top three, and then provided detail on the five-year plan.

The top-rated area was communication for wireless control. The identified needs are as follows:

1) Assess what technologies are already out there in other fields, and how they can be applied in buildings.

2) Create and support standards for interoperability.

3) Research the potential for building control with wireless sensing and communication.

In addition, there is a need for standards to allow integration of wireless systems into existing building automation systems. Power scavenging should also receive some attention as well as further miniaturization to develop smaller sensors, increasing the range over which such devices can communicate, and extending to higher temperatures (for use in boilers, for example).

The second priority area was advanced sensors. Specific sensor concepts include

1) Volumetric air flow sensing

2) Low-cost power metering to see where the power is being used in buildings

3) Low-cost humidity sensors at about $\$ 10$ per sensor, compared to current costs of $\$ 100$ per sensor

4) A whole set of indoor air quality sensors to measure concentrations of $\mathrm{CO}_{2}$, mold, pollen, etc.

5) Biochemical and chemical sensors for threat detection with an emphasis on the security of building HVAC systems. (We assume this would require detection outside the 
building envelope, but they could also detect contaminants released from within the building.)

Over the longer term, self-configuring, self-calibrating sensors should be investigated.

The third area was testing and qualifying sensors. The goal is not only to understand the limits of sensors, and improvements needed, but also to determine optimal selection and placement. Areas for further investigation are

1. Identification and characterization of testing conditions, e.g., threat conditions, temperature, and humidity.

2. Development of test procedures.

3. Development of a test facility and of a human interface test facility. 


\subsection{NETWORKING, SECURITY, AND PROTOCOLS AND STANDARDS}

\subsection{Overview}

Workshop participants envision a future where buildings will be monitored and operated remotely. This additional capability will need to be addressed not only from a protocol and standards perspective, but perhaps more importantly, from a security perspective. This is a new area for building networking protocols.

There are additional desired capabilities in distributed intelligence and systems integration. Consideration must be given as to what protocols will be required to allow these new services and technologies to develop. What does the network need to look like to handle these new technologies? What are the security requirements for these new technologies? To what degree is "backwards compatibility" desired and what are the hurdles to this capability?

If we add to this the ability to respond to changing prices for energy, in real time, additional levels of complexity may ensue. As a result of utility deregulation, reserve margins may go down which increases price volatility. Buildings can have the capability to respond to increasing prices by shedding load (decreasing demand). Currently, there is limited market structure that allows (rewards) a building owner for shedding load based on the total utility system demand. As the ability for demand response adds additional complexity to building operation, more research is required to develop a theory of how this market will operate. There will be a fundamental shift from local control (the building operator) to global control of a building (by building owners or managers, or utilities). Security is but one aspect of interoperability that will have to span a range of building infrastructure(s).

Beyond remote control of buildings, there is also the possibility of information sharing with outside partners (utilities, energy service companies, vendors). This information could be used for performance monitoring and diagnostics, or something as simple as billing. This type of sharing could extend to application sharing where different operators have to control different aspects of building operation from both inside and outside the building. There are also issues of data ownership.

Immediate issues arise as to who owns the network (if it is shared on a local computer LAN). How are decisions made as to how many devices can connect so as not to overwhelm the network? Consideration must be given to network architecture and all associated components including cabling and existing standards. Self-configuring, self-healing networks are one answer to the increased demand for network standards. 
BACNet is one of several options. But BACNet does not have to be the answer for all these increased services and needs. For instance, many industries are using XML to share data. Also, BACNet can be used for some features, but it is not necessarily the answer to security issues.

\subsection{Workshop Results}

A primary research focus should be the utility networking requirements. What does the connection to the utility look like? An initial step would be to develop a first principles model that looks at the building-utility interface. A second step is to work with the appropriate standards organizations to define what is needed and to get these standards in place.

Another area of focus is security. This includes the security framework not only between buildings and utilities, but also anywhere else data or control might travel inside or outside the building. This is not only an issue for existing applications, but must also be considered for future applications.

A final area is to reduce the cost and complexity of networking through development of "Smart Networks.” This includes developing an information model to enable

- $\quad$ self-configuration

- $\quad$ self-healing network

- information exchange

- self-documentation.

This includes how to report and convey information to applications (e.g., access control, lighting, and ventilation) based on knowledge of occupancy. Finally, what would be required in the protocol and what is required in the network? 


\subsection{Automated Diagnostics, Performance MEASUREMENT, COMMISSIONING AND OPTIMAL CONTROL AND TOOLS}

\subsection{Overview}

Many buildings control systems are essentially "broken.” Energy systems are malfunctioning or disabled. Unfortunately, there is a lack of systematic information available as to the causes, remediation efforts, and paybacks. More information is needed.

The ultimate question is what is the size of the actual energy savings opportunity? Texas A\&M has an established approach to "tuning up" existing buildings. Their team has been able to achieve energy savings of $20 \%$ with less than a two-year payback just from fixing faults and finetuning control strategies.

More information is needed on identifying typical problems in buildings and the best way to address them. Information is also required on the persistence level of savings through time, and on non-energy benefits.

A key to addressing wasteful energy use in buildings is getting the right information in a useful format. This is the essence of performance monitoring. Good visualization tools and the ability to compare performance with historical performance are also needed. Current EMCSs have poor capabilities and do not provide the right kinds of measurement.

Tools are also needed to perform automated diagnostics. These tools should provide both fault detection and diagnosis. An additional desired capability is active testing. Automated diagnostics falls into two categories. Some manufacturers supply diagnostics with individual components. Other firms are attempting to aggregate these component-based diagnostics to systems targeted at the whole building level (or higher).

Commissioning is hand-crafted. The process is manual, which increases costs and decreases the ability to replicate the process. Much commissioning is done in-house but is not labeled commissioning. Instead, it is labeled as repairs and maintenance. This process needs to be automated so that it can be shared and replicated. The ability to retro-commission is limited by the lack of poor benchmarks from bad or non-existent commissioning when the building was new.

Optimal control is the ability to manage energy use so as to maximize performance for the dollar. This includes responding to price changes and, when possible, shifting electricity consumption to off-peak hours. Two possible paths are to implement optimal control on-line in the building or conduct lab-based research to develop heuristic strategies that approximate optimal control and are potentially more robust. Optimal control can be expected to provide greater benefits when the 
building includes thermal storage and/or on-site electricity generation to address peak load issues. While energy savings might be modest, cost savings can be significant. The buildings industry can learn from other process industries that are already doing this.

While there are very good building design tools, none at present includes the ability to model control strategies. This limits consideration of controls for eventual inclusion in the final design. The result is sub-optimal design from an energy standpoint.

\subsection{Workshop Results}

This topic area included diagnostics, performance measurement, commissioning, and optimal control as well as tools. The workshop participants gave equal weighting to the importance of all these $R \& D$ areas except commissioning. Commissioning received no votes.

There are three areas included in performance monitoring:

1) Data management - These is a lot of data but storage and use is never centralized. Data protocols are needed.

2) Sensor location - Proper location is not very well understood now and may get worse as the sensors move throughout the building.

3) Analysis tools - Tools need to be integrated.

In the first two years, the research should focus on best practices for sensor selection and placement. Years three through five will focus on development of integrated tools and the extension to peak demand. An effort will also be needed in the area of data management.

Additional case studies are needed to determine the cost and benefits of commissioning. ${ }^{8}$ Development of standardized tests should be the focus of the first two years. In years three through five, additional test methods should be developed and validated to determine their ability to achieve energy savings. In the longer term, research should focus on sensors that can "rediscover" building layout and usage to inform commissioning.

Two areas were identified for automated diagnostics:

1) Fault detection - What are the best methods and how can they be integrated?

2) Prioritization of faults - Which faults require more attention than others?

\footnotetext{
${ }^{8}$ Editor's Note. Such a study was completed subsequent to the workshop. See Evan Mills, et al., "The Cost-Effectiveness of Commercial-Buildings Commissioning: A Meta-Analysis of Energy and Non-Energy Impacts in Existing Buildings and New Construction in the United States," Lawrence Berkeley National Laboratory, LBNL-56637, December 2004.” Also available at: http://eetd.lbl.gov/emills/PUBS/Cx-CostsBenefits.html
} 
The first two years will focus on development, testing, and ranking of fault detection and diagnostic systems for standard systems and components. In out-years, this process will be extended to new systems.

Tools are needed for active tests that address the interactions between systems, e.g., HVAC and lighting controls. These tools should be tied to simulation models. Work should include improved interfaces as well as national, web-based access to these tools. 


\section{ApPendix A}

Workshop Agenda 


\title{
Appendix A - Workshop Agenda
}

\section{U.S. DOE Advanced Controls R\&D Workshop}

\section{Objective}

\author{
June 11, 2003, Washington, DC
}

Obtain review and input of the U.S. Department of Energy's assessment of the market for advanced controls technology and potential R\&D pathways to enhance the success of advanced controls in the buildings market place.

\begin{tabular}{|c|c|c|}
\hline Time & Event & Presenter \\
\hline $8: 30-9: 00$ & \multicolumn{2}{|l|}{ Refreshments and Registration } \\
\hline 9:00-9:15 & Welcome and Overview & \begin{tabular}{|l|} 
David Hansen, US DOE \\
\end{tabular} \\
\hline 9:15-9:30 & \begin{tabular}{|l} 
Agenda and Format \\
\end{tabular} & Sean McDonald, PNNL \\
\hline $9: 30-10: 00$ & Market Assessment & Kurt Roth, TIAX \\
\hline $10: 00-10: 15$ & \multicolumn{2}{|l|}{ Break } \\
\hline 10:15-10:45 & $\begin{array}{l}\text { Current Applications and Strategies for } \\
\text { New Applications }\end{array}$ & \begin{tabular}{|l} 
Paul Torcellini, NREL \\
\end{tabular} \\
\hline 10:45-11:15 & Sensors and Controls & \begin{tabular}{|l|} 
Michael Brambley, PNNL \\
\end{tabular} \\
\hline 11:15-11:45 & $\begin{array}{l}\text { Networking, Security, and Protocols } \\
\text { and Standards }\end{array}$ & David Holmberg, NIST \\
\hline 11:45-12:15 & $\begin{array}{l}\text { Auto. Diag., Perf. Monitoring, Comm., } \\
\text { Optimal Control and Tools }\end{array}$ & Philip Haves, LBNL \\
\hline $12: 15-1: 00$ & $\begin{array}{l}\text { "Outside the Box" Lunch } \\
\text { (Lunch Provided) }\end{array}$ & $\begin{array}{l}\text { Short presentations during lunch } \\
\text { to get people thinking "outside } \\
\text { the box." }\end{array}$ \\
\hline 1:00-2:15 & $\begin{array}{l}\text { Breakout Sessions } \\
\text { - Response to presentation Q\&A } \\
\text { - Refinements to R\&D options } \\
\end{array}$ & \\
\hline $2: 15-2: 30$ & \multicolumn{2}{|l|}{ Break } \\
\hline 2:30-3:00 & \begin{tabular}{|l} 
Breakout Sessions \\
$\qquad \quad \begin{array}{l}\text { Prioritization of R\&D } \\
\text { opportunities }\end{array}$ \\
\end{tabular} & \\
\hline $3: 00-4: 15$ & $\begin{array}{l}\text { Presentation of Breakout sessions } \\
\text { - Current and New Applications } \\
\text { - Sensors and Controls } \\
\text { - Networking, Sec, Protocols \& } \\
\text { - Standards } \\
\text { - Automated Diag, PM, Comm. } \\
\text { and Optimal Control and Tools }\end{array}$ & White Paper Leads \\
\hline 4:15-4:45 & $\begin{array}{l}\text { Cross-Cutting Issues \& "Outside the } \\
\text { box" }\end{array}$ & Sean McDonald, PNNL \\
\hline 4:45-5:00 & Next Steps & David Hansen, DOE \\
\hline $5: 00$ & \multicolumn{2}{|l|}{ Adjourn } \\
\hline
\end{tabular}




\section{APPENDIX B}

\section{Workshop Attendees}




\section{APPENDIX B - WORKSHOP ATTENDEES}

Don Anderson, Principal

ICF Consulting Inc

9300 Lee Highway

Fairfax, VA 22301

phone: (703) 218-2774

fax: (703) 934-3974

email: DAnderson@icfconsulting.com

Karen Benedek

TIAX, LLC

15 Acorn Park

Cambridge, MA 02140-2328

phone: (617) 498-6061

fax: (617) 498-7206

email: benedek.k@tiax.biz

David Bornside, Senior Principal Engineer

Siemens Building Technologies

1000 Deerfield Parkway

Buffalo Grove, IL 60089

phone: (847) 941-5422

email: david.bornside@siemens.com

J oseph Borowiec, Associate Project Manager

NYSERDA

Building R\&D

17 Columbia Circle

Albany, NY 12203

phone: (518) 862-1090 ext. 3381

fax: (518) 862-1091

email: jcb@nyserda.org

Michael Brambley, Staff Scientist

Pacific Northwest National Laboratory

P.O. Box 999, MS K5-16

Richland, WA 99352

phone: (509) 375-6875

fax: (509) 375-3614

email: michael.brambley@pnl.gov
Martha Brook, P.E., Senior Mechanical

Engineer

California Energy Commission

MS-42

1516 Ninth Street

Sacramento, CA 95814

phone: (916) 654-4086

fax: (916) 651-8886

email: MBrook@energy.state.ca.us

Karl Brown

California Institute for Energy Efficiency

1333 Broadway Suite 240

Oakland, CA 94612

phone: (510) 287-3330

email: karl.brown@ucop.edu

Steven Bushby

NIST

Building Environment Division (863)

100 Bureau Drive, Stop 8631

Gaithersburg, MD 20899-8631

phone: (301) 975-5873

email: steven.bushby@nist.gov

Ronald Caffrey

BCS Partners

2008 Carolina Circle N.E.

St. Petersburg, FL 33703

phone: (727) 528-9684

fax: (same - call first)

email: rcaffrey@tampabay.rr.com

Michael Chapman, Senior Architect, CHENG

Naval Facilities Engineering Command

Design Policy/Architecture

1322 Patterson Avenue, SE

Washington Navy Yard

Washington, DC 20374-5065

phone: (202) 685-9175

fax: (202) 685-1577

email: MCHAPMAN@navfac.navy.mil 
David Claridge, Professor

Texas A\&M University

Department of Mechanical Engineering

College Station, TX 77843-3123

phone: (979) 845-1280

fax: (979) 862-2762

email: Claridge@esl.tamu.edu

Dru Crawley

U.S. Department of Energy

1000 Indepedence Ave, SW, EE-2]

Washington, DC 20585

phone: (202) 586-2344

fax: (202) 586-5557

email: drury.crawley@ee.doe.gov

Paul Ewing, Leader

RF \& Microwave Systems Group

Oak Ridge National Laboratory

One Bethel Valley Road

Building 3500 MS 6006 Room B18

PO Box 2008

Oak Ridge, TN 37831-6006

phone: (865) 576-5019

email: ewingpd@ornl.gov

Kevin Finnegan, Senior Project Manager

Battery Park City Authority

One World Financial Center

New York, NY 10281-1097

phone: (212) 416-4330

fax: (212) 416-5314

email: FinneganK@bpcauthor.org

Theo Frutiger, System Architect

Siemens Building Technologies

Siemens SBT HVAC Products

1000 Deerfield Parkway

Buffalo Grove, IL 60089

phone: (847) 941-6255

fax: (847) 941-4721

email: theo.frutiger@siemens.com

Vijay Gupta, Senior Mechanical Engineer

U.S. General Services Administration

Office of the Chief Architect

1800 F Street, NW

Washington, DC 20405

phone: (202) 501-0628

fax: (202) 501-3393

email:Vijay.Gupta@gsa.gov
David Hansen

U.S. Department of Energy

1000 Independence Ave, SW, EE-2J

Washington, DC 20585

phone: (202) 586-9192

fax: (202) 586-5557

email: david.hansen@ee.doe.gov

Tom Hartman

The Hartman Company

9905 39th Drive NE

Marysville, WA 98270

phone: (360) 658-1168

fax: (360) 658-1178

email: thartman@hartmanco.com

Philip Haves

Lawrence Berkeley National Laboratory

Building 90, MS 90-3074

1 Cyclotron Road

Berkeley, CA 94720

phone: (510) 486-6512

fax: (510) 486-4089

email: PHaves@lbl.gov

David Holmberg

NIST

Building Environment Division (863)

100 Bureau Drive, Stop 8631

Gaithersburg, MD 20899-8631

phone: (301) 975-6450

email: david.holmberg@nist.gov

John House

Iowa Energy Center

Suite 124

2521 Elwood Drive

Ames, lowa 50010-8263

phone: (515) 294-0111

fax: (515) 294-9912

email: jhouse@energy.iastate.edu

Steve Karg

Lithonia Lighting

One Lithonia Way

Building 1

Decatur, GA 30035

phone: (770) 987-4200

email: skarg@lithonia.com 
Roger Kisner

Oak Ridge National Laboratory

One Bethel Valley Road

Building 37831 MS 6004

P.O. Box 2008

Oak Ridge, TN 37831-6004

phone: (865) 574-5567

email: kisnerra@ornl.gov

Ron Lewis

U.S. Department of Energy

1000 Independence Ave, SW, EE-2J

Washington, DC 20585

phone: (202) 586-8423

email: ronald.lewis@ee.doe.gov

Eric Lightner

U.S. Department of Energy

Office of Electric Transmission and

Distribution

1000 Independence Ave, SW, EE-2D

Washington, DC 20585

phone: (202) 586-8130

fax: (202) 586-5860

email: eric.lightner@ee.doe.gov

Vivian Loftness

Carnegie Mellon University

Architecture Department

Head of the School of Architecture

500 Forbes Avenue

4919 Frew St. Room 201

Pittsburgh, PA 15213

phone: (412) 268-2356

email: loftness+@andrew.cmu.edu

Tom Lohner, Vice President

Teng \& Associates

4050 Innslake Drive

Suite 300

Glen Allen, VA 23060-3327

phone: (804) 474-4550

fax: (804) 474-4555

email: lohnertj@teng.com

Sean McDonald

Pacific Northwest National Laboratory

901 D Street, SW

Suite 900

Washington, DC 20024

phone: (202) 646-5217

fax: (202) 646-5233

email: sean.mcdonald@pnl.gov
J ohn McKissack, P.E.

The Kele Companies

3300 Brother Boulevard

Memphis, TN 38133

phone: (901) 382-4300 ext. 3770

fax: (901) 372-2531

email: johnm@kele.com

Terrence McMahon

BCS Partners

135 Fort Lee Road

Leonia, NY 07605

phone: (201) 585-2050

fax: (201) 585-1968

email: mcmahontec135@aol.com

Mark Myers, Research Fellow

United Technologies Research Center

411 Silver Lane

Mail Stop 129-85

East Hartford, CT 06108

phone: (860) 610-7538

fax: (860) 660-1288

email: MyersMR@UTRC.UTC.COM

Kurt Roth

TIAX, LLC

15 Acorn Park

Cambridge, MA 02140-2328

phone: (617) 498-6062

email: roth.kurt@tiax.biz

J ohn Ryan

U.S. Department of Energy

1000 Independence Ave, SW, EE-2]

Washington, DC 20585

phone: (202) 586-8823

fax: (202) 586-4617

email: john.d.ryan@ee.doe.gov

Harvey Sachs, Director

ACEEE

Buildings Programs

1001 Connecticut Ave NW, Suite 801

Washington, DC 20036

phone: (202) 478-7706

email: hsachs@aceee.org 
Michael K. Sahm

Research Fellow \& Energy System Group

Leader

United Technologies Research Center

411 Silver Lane

Mail Stop 129-65

East Hartford, CT 06108

phone: (860) 610-7605

fax: (860) 660-1358

email: SahmMK@UTRC.UTC.COM

J effrey Schein

NIST

Building Environment Division (863)

100 Bureau Drive, Stop 8631

Gaithersburg, MD 20899-8631

phone: (301) 975-5874

email: jeffrey.schein@nist.gov

J ohn Seem

Johnson Controls

507 East Michigan Street

Mail Stop M36

Milwaulkee, WI 53202

phone: (414) 524-4677

fax: (414) 524-5810

email: John.E.Seem@jci.com

Sandy Smith

ACEEE

Buildings Programs

1001 Connecticut Ave NW, Suite 801

Washington, DC 20036

phone: (202) 478-7700

email: ssmith@aceee.org

Mike Stein

Mike Stein Associates

40 Alize Drive

Kinnelon, NJ 07504

phone: (973) 838-8140

fax: (973) 838-8035

email: mike.stein@worldnet.att.net
Randal Stites, Engineering Manager

Hines GS Properties, Inc.

901 D. Street, SW

Box 18, Suite 290

Washington, DC 20024-2169

phone: (202) 484-8181

fax: (202) 484-0579

email: randal_stites@hines.com

Paul Torcellini

National Renewable Energy Laboratory

1617 Cole Blvd

Mail Stop 2722

Golden, CO 80401-3393

phone: (303) 384-7528

fax: (303) 384-7540

email: Paul_Torcellini@nrel.gov

Stephen Treado

NIST

Building Environment Division (863)

1000 Bureau Drive, Stop 8631

Gaithersburg, MD 20899-8631

phone: (301) 975-6444

email: stephen.treado@ist.gov

Martin Weiland

Manager of Government Outreach

ASHRAE

1828 L St. N.W., Suite 906

Washington, DC 20036-5104

phone: (202) 833-1830

fax: (202) 833-0118

email: mweiland@ashrae.org

Robert Williams

Continental Automated Buildings Association

(CABA)

4200 NW 74th Court

P.O. Box 901525

Kansas City, MO 64151

phone: (816) 746-4320

fax: (212) 202-4493

email: bobwilliams23@aol.com or bobwilliams23@sbdcglobal.com 


\section{Appendix C}

\section{R\&D Worksheets}


Page 30 


\section{C.1 Sensors and Controls}

R\&D Program Area: Sensors and Controls

R\&D Project Activity: Communication: Wired vs. Wireless

Team members:

Completed by:

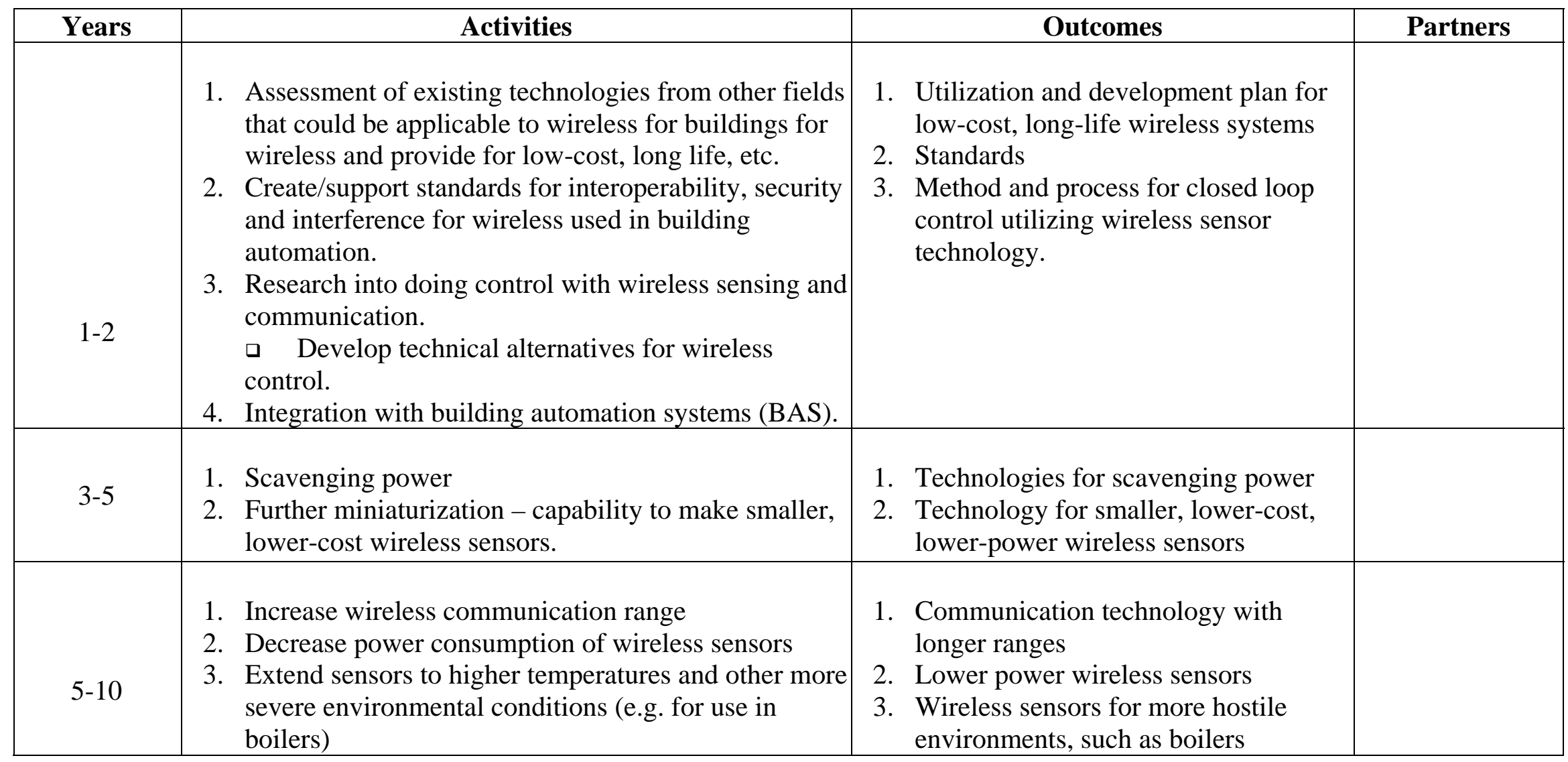


R\&D Program Area: Sensors and Controls R\&D Project Activity: Advanced Sensors Team members:

Completed by:

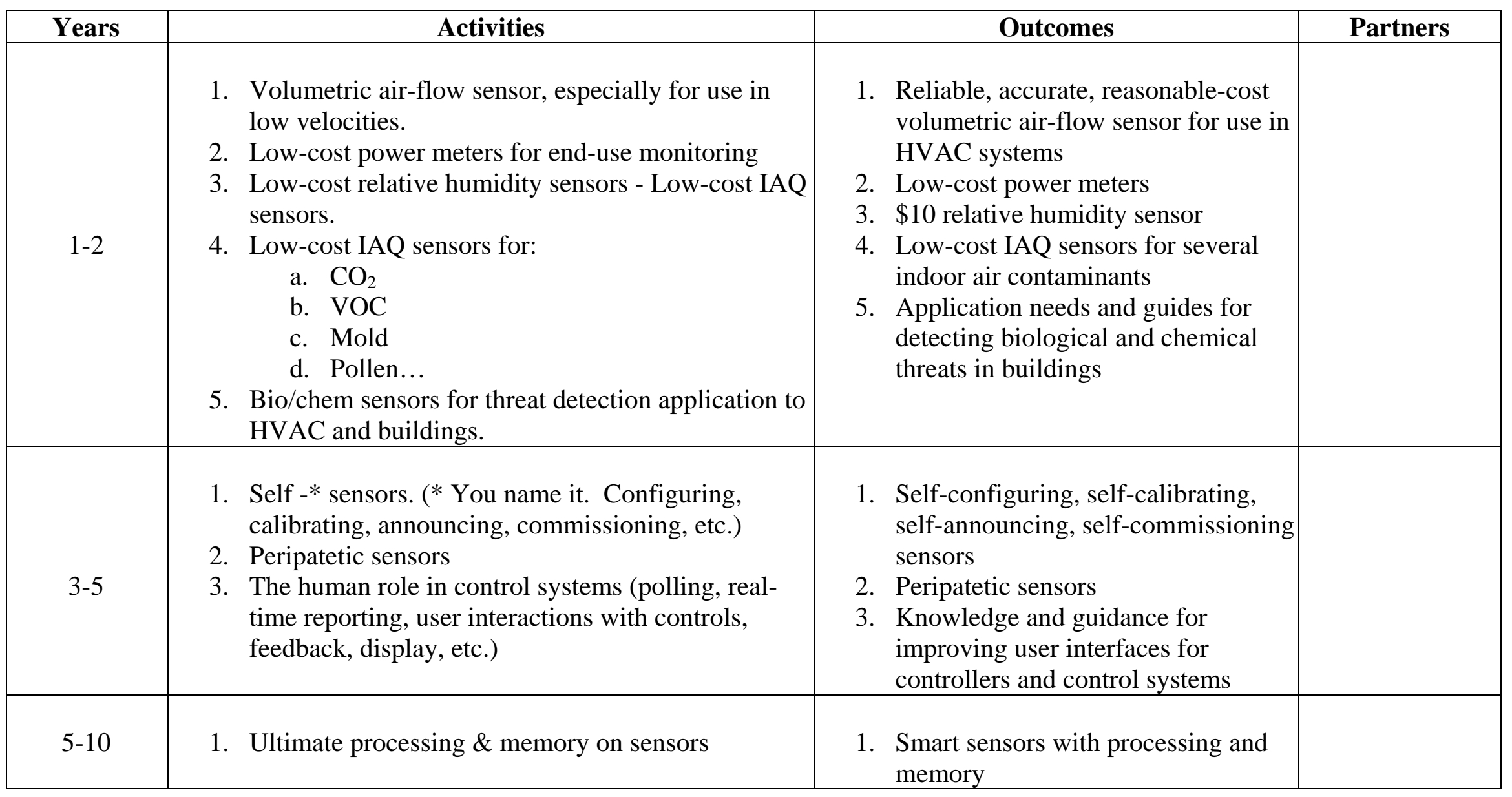


R\&D Program Area: Sensors and Controls

R\&D Project Activity: Testing \& Qualifying Sensors, Control Systems, and Human Interfaces

Team members:

Completed by:

\begin{tabular}{|c|c|c|c|}
\hline Years & Activities & Outcomes & Partners \\
\hline $5-10$ & & & \\
\hline
\end{tabular}




\section{C.2 Networking, Security Protocols \& Standards}

R\&D Program Area: Networking, Security Protocols \& Standards

R\&D Project Activity: Protocols \& Standards

Team members: David Holmberg, Steve Bushby, Paul Ewing, Steve Karg, Terry McMahon

Completed by: David Holmberg

\begin{tabular}{|c|l|c|c|}
\hline Years & \multicolumn{1}{|c|}{ Activities } & Outcomes & \multicolumn{1}{|c|}{ Partners } \\
\hline $1-2$ & $\begin{array}{l}\text { ID information needs for protocols to enable new } \\
\text { network tech/services }\end{array}$ & \\
& $\begin{array}{l}\text { ID security needs in protocols } \\
\text { Analyze BCS -lights (HVAC-lights) interconnection }\end{array}$ & \\
\hline $3-5$ & Demos & $\begin{array}{l}\text { Publish studies } \\
\text { Reference designs }\end{array}$ & \\
\hline $5-10$ & & & \\
\hline
\end{tabular}


R\&D Program Area: Networking, Sec Protocols \& Protocol Standards

R\&D Project Activity: Utility-Networking Requirements

Team members: David Holmberg, Steve Bushby, Paul Ewing, Steve Karg, Terry McMahon

Completed by: David Holmberg

\begin{tabular}{|c|l|l|l|}
\hline Years & \multicolumn{1}{|c|}{ Activities } & \multicolumn{1}{c|}{ Outcomes } & \multicolumn{1}{c|}{ Partners } \\
\hline \multirow{5}{*}{$1-2$} & $\begin{array}{l}\text { First principal model of complex controls } \\
\text { Works with ASHRAE, EPRI, IEEE on } \\
\text { communication studies (formats, transport } \\
\text { information requirements, security) NT-MT }\end{array}$ & $\begin{array}{l}\text { EPRI } \\
\text { ASHRAE } \\
\text { Security framework to enable BCS utility intercross } \\
\text { Lab demos services/proof-of-concept } \\
\text { What can DOE do to facilitate RTP }\end{array}$ & $\begin{array}{l}\text { Georgia } \\
\text { Power } \\
\text { GE Power } \\
\text { Systems } \\
\text { DOE }\end{array}$ \\
\hline $3-5$ & $\begin{array}{l}\text { Demonstrate: field test } \\
\text { Inter-operability of “new” with “old” }\end{array}$ & Educational documents \\
\hline
\end{tabular}


R\&D Program Area: Networking, Sec Protocols \& Protocol Standards

R\&D Project Activity: Smart Networking

Team members: David Holmberg, Steve Bushby, Paul Ewing, Steve Karg, Terry McMahon

Completed by: David Holmberg

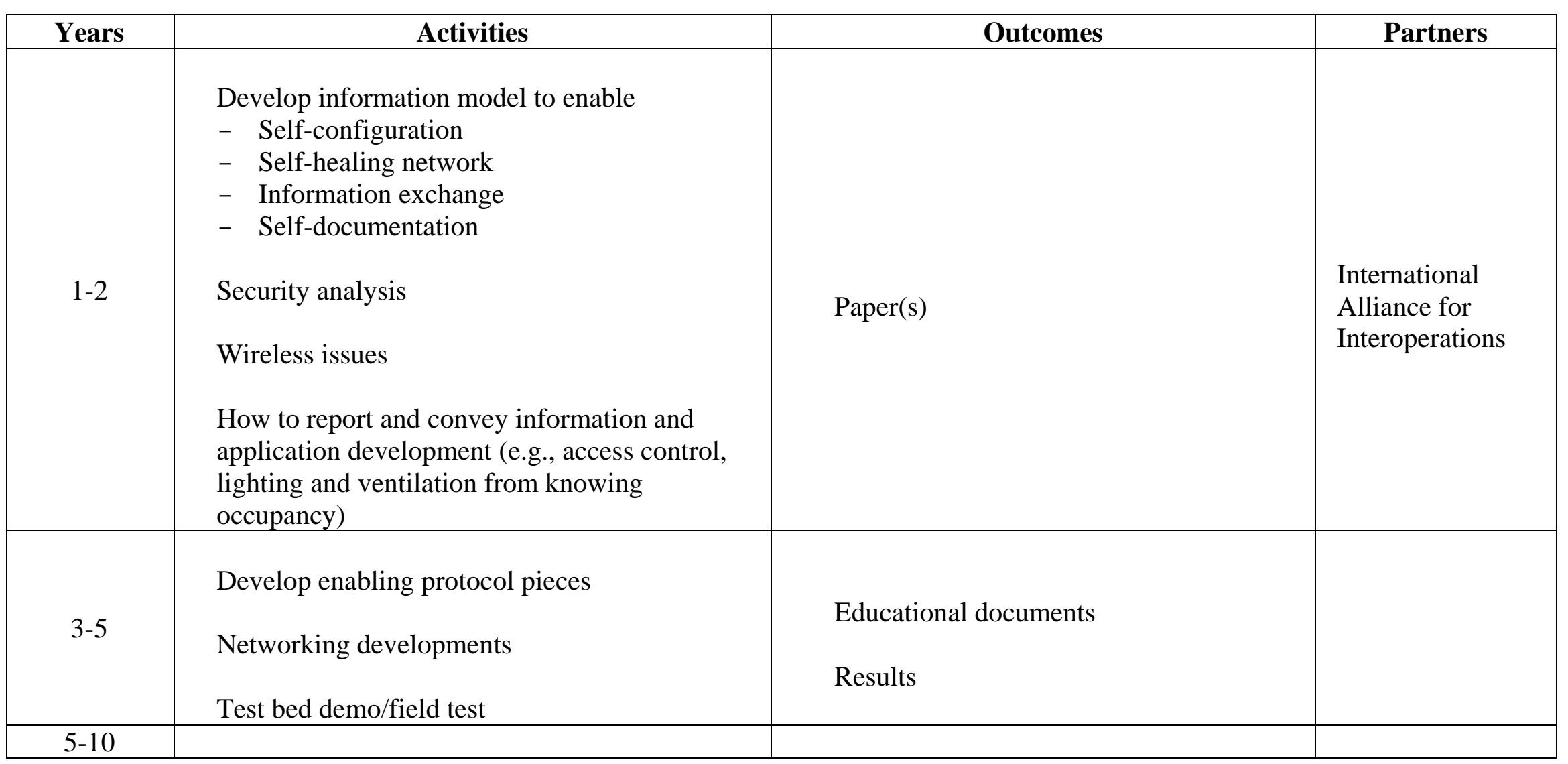




\section{C.3 Current and New Applications}

R\&D Program Area: Current and New Applications

R\&D Project Activity: Next Generation User \& Automatic Controls

Team members:

Completed by:

\begin{tabular}{|c|c|c|c|}
\hline Years & Activities & Outcomes & Partners \\
\hline $1-2$ & $\begin{array}{l}\text { Establish statement of work performance goals } \\
\text { for "skunkworks" teams and RFQ for assemble } \\
\text { teams (Lighting \& HVAC) } \\
\text { ' } 3 \text { ' teams (each) complete paper studies of } \\
\text { hardware choices and controls issues to develop } \\
\text { conceptual alternatives - select one team } \\
\text { identify regional design issues }\end{array}$ & $\begin{array}{cl}\text { e.g. Lighting: high level of control } \\
-\quad \text { Self configure } \\
-\quad \text { Reconfigurable fixture location and } \\
\text { zone control } \\
-\quad \text { User satisfaction } \\
-\quad \text { Out-of-the-box installation } \\
\quad \text { performance (no commission) } \\
\text { - } \quad \text { Energy efficiency: annual, peak, } \\
\quad \text { demand with user feedback } \\
\text { - } \quad \text { Daylight performance façade } \\
\text { - No parasitic loads } \\
\text { e.g., HVAC } \\
\text { Introducing cooling/ventilation in existing } \\
\text { buildings without air conditioning now, } \\
\text { while maintaining natural ventilation. } \\
\text { Performance goals: } \\
\text { High-level of user satisfaction } \\
\text { ASHRAE standards } \\
\text { Energy efficiency: annual, peak, } \\
\text { demands } \\
\text { Robust, low O\&M }\end{array}$ & $\begin{array}{l}\text { Mfg x } 3 \\
\text { Fixture } \\
\text { Ballast } \\
\text { Controller } \\
\text { Façade Controls } \\
\text { Lamp } \\
\text { Installer } \\
\quad \text { - GSA-End } \\
\quad \text { User/ERGO }\end{array}$ \\
\hline
\end{tabular}




\begin{tabular}{|c|c|c|c|}
\hline & & $\begin{array}{l}\text { No commission/out-of-the box install } \\
\text { High-level of user control-untrained user } \\
\text { No parasitic load } \\
\text { Natural ventilation/cooling effectiveness } \\
\text { Dynamic zone control/modification } \\
\text { - Acoustic control }\end{array}$ & $\begin{array}{l}\text { All } 3 \text { teams in } \\
\text { each should } \\
\text { succeed with } \\
\text { variations in cost/ } \\
\text { performance } \\
\text { choices - key to } \\
\text { competitive } \\
\text { supply for federal } \\
\text { sector. }\end{array}$ \\
\hline $3-5$ & $\begin{array}{l}\text { Engineering and prototyping of complete } \\
\text { systems, testing with untrained installer and } \\
\text { controls performance with untrained user. } \\
\text { Demonstration/field project measurement } \\
\text { including health and productivity gains. } \\
\text { Life cycle costing based on volume production } \\
\text { Take plug and play conditioning system to } \\
\text { market }\end{array}$ & & \\
\hline $5-10$ & & & \\
\hline
\end{tabular}


R\&D Program Area: Current and New Applications

R\&D Project Activity: Tools and Simulation

Team members: John Ryan

Completed by:

\begin{tabular}{|c|c|c|c|}
\hline Years & Activities & Outcomes & Partners \\
\hline $1-2$ & $\begin{array}{l}\text { Design Phase (steady state) } \\
\text { - } \text { Catalog equipment configurations \& } \\
\text { - } \\
\text { Control strategies } \\
\text { Characterize a subset of hardware } \\
\text { - } \\
\text { Develop software and lab test against } \\
\text { research data. }\end{array}$ & $\begin{array}{l}\text { Design Phase } \\
\text { Tool that will simulate operation of subsystem } \\
\text { controls in standalone mode } \\
\text { - Lighting } \\
-\quad \text { HVAC } \\
\quad 0 \text { Common systems } \\
0 \text { Less common }\end{array}$ & \\
\hline $3-5$ & $\begin{array}{l}\text { Field test subsystem models } \\
\text { Lighting } \\
\text { HVAC } \\
\text { Add EMCS and utility modules }\end{array}$ & $\begin{array}{l}\text { Tool that simulates EMCS - whole } \\
\text { building including utility interface }\end{array}$ & \\
\hline $5-10$ & $\begin{array}{l}\text { Operational Phase (steady state) } \\
\text { - } \quad \text { Data collection thru EMCS }\end{array}$ & $\begin{array}{l}\text { Tool that simulates operational control } \\
\text { system: sensor locations, piping } \\
\text { configuration as built } \\
\text { - } \quad \text { Embodied in EMCS system }\end{array}$ & \\
\hline
\end{tabular}


R\&D Program Area: Current and New Applications

R\&D Project Activity: Optimization of Existing Systems

Team members:

Completed by:

\begin{tabular}{|c|c|c|c|}
\hline Years & Activities & Outcomes & Partners \\
\hline $1-2$ & $\begin{array}{l}\text { Measure building that used design tools - } \\
\text { actual energy } \\
\text { Study using tools to assess potential } \\
\text { Determine viability/need for real-time } \\
\text { optimization } \\
\text { Benchmark optimization from other industries } \\
\text { find parallel industries }\end{array}$ & $\begin{array}{l}\text { Access what is potential of real-time control } \\
\text { vs. control }\end{array}$ & $\begin{array}{l}\text { Universities, } \\
\text { DOE } 2 \text { users } \\
\text { Building } \\
\text { Operators }\end{array}$ \\
\hline $3-5$ & & $\begin{array}{l}\text { How does hierarchal control approach account } \\
\text { for } \\
\begin{aligned} \text { - } & \text { DG/PV } \\
\text { - } & \text { pricing } \\
\text { - } & \text { inter-system priorities/interplay/affects } \\
\text { - } & \text { load shedding }\end{aligned}\end{array}$ & \\
\hline $5-10$ & $\begin{array}{l}\text { Development of optimization science } \\
\text { Implementation of optimization strategies } \\
\text { document savings }\end{array}$ & & \\
\hline
\end{tabular}


R\&D Program Area: Current and New Applications

R\&D Project Activity: Dynamic Envelop Control Integration (Lighting, thermal ventilation, chemical/bio filter)

Team members:

Completed by:

\begin{tabular}{|c|c|c|c|}
\hline Years & Activities & Outcomes & Partners \\
\hline $1-2$ & $\begin{array}{l}\text { Benchmark current technologies world wide } \\
\text { Survey current product development and } \\
\text { research } \\
\text { - } \text { design research } \\
\text { - } \text { technical product research } \\
-\quad \text { industry } \\
\text { - national labs } \\
\text { Workshops on regional climatic design } \\
\text { responses }\end{array}$ & $\begin{array}{l}\text { Report on challenges for each climatic zone } \\
\text { and recommendations for further design } \\
\text { development }\end{array}$ & $\begin{array}{l}\text { - GSA } \\
\text { - DoD } \\
\text { - A-E Industry } \\
\text { - Academia } \\
\text { - Building } \\
\text { Technology } \\
\text { Industry } \\
\text { o Lighting } \\
\text { o Envelope } \\
\text { o HVAC } \\
\text { - ASHRAE }\end{array}$ \\
\hline $3-5$ & $\begin{array}{l}\text { Competitive prototyping of complete } \\
\text { systems - next-generation } \\
\quad \text { - Switch filters (dynamic) envelops } \\
\text { DOE \& partner-funded demonstration } \\
\text { projects - regionally focused } \\
\text { Control strategies for interaction of } \\
\text { equipment }\end{array}$ & $\begin{array}{l}\text { Samples of next-generation prototype } \\
\text { envelopes } \\
\text { Performance data- regionally defined }\end{array}$ & \\
\hline $5-10$ & $\begin{array}{l}\text { Completed pilot projects of next-generation } \\
\text { envelopes with evaluation data }\end{array}$ & $\begin{array}{l}\text { Regional guidelines for envelop design with } \\
\text { performance data }\end{array}$ & \\
\hline
\end{tabular}




\section{C.4 Automated Diagnostics, PM, Communication \& Optimal Control Tools}

R\&D Program Area: Automated Diagnostics, PM, Communication \& Optimal Control Tools

R\&D Project Activity: Performance Monitoring

Team members:

Completed by:

\begin{tabular}{|c|l|l|l|}
\hline Years & \multicolumn{1}{|c|}{ Activities } & \multicolumn{1}{c|}{ Outcomes } \\
\hline $1-2$ & $\begin{array}{l}\text { Data Management } \\
\text { Integration } \\
\text { Quality validation } \\
\text { Std protocol EMCS access } \\
\text { Sensor selection and location (best practice) } \\
\text { guidance }\end{array}$ & Protocol, approaches, algorithms \\
\hline $3-5$ & $\begin{array}{l}\text { Analysis tools (e.g., peak demand) } \\
\text { Validate with operators. Enhance visualization. }\end{array}$ & Integrated tool options \\
\hline $5-10$ & $\begin{array}{l}\text { Sensor selection and location (advanced) } \\
\text { Extend previous year's efforts as needed }\end{array}$ & Advanced guidance \\
\hline
\end{tabular}


R\&D Program Area: Automated Diagnostics, PM, Comm. \& Optimal Control Tools

R\&D Project Activity: Automated Diagnostics

Team members:

Completed by:

\begin{tabular}{|c|c|c|c|}
\hline Years & Activities & Outcomes & Partners \\
\hline $1-2$ & $\begin{array}{l}\text { Develop, test and rank Fault Detection and } \\
\text { Diagnostics (FDD) methods for standard } \\
\text { systems and components (e.g. chillers, AHUs, } \\
\text { VAVs } \\
\text { - Includes passive and active testing } \\
\text { - } \\
\text { Crosscutting leverage what's been developed } \\
\text { in other (non-buildings) industries. }\end{array}$ & $\begin{array}{l}\text { Prioritization of faults } \\
\quad \text { - High occurrence and impacts } \\
\text { Prioritization of methods (convergence on } \\
\text { "best practice”) } \\
\text { Functional testing methods (consistent } \\
\text { between crosscutting and Automated Fault } \\
\text { Detection and Diagnostics (AFDD) }\end{array}$ & \\
\hline $3-5$ & $\begin{array}{l}\text { Develop and test FDD methods for other/new } \\
\text { systems and components } \\
\text { - Common factor across components - } \\
\text { system diagnostics }\end{array}$ & Methods of test (ASHRAE) & \\
\hline $5-10$ & & & \\
\hline
\end{tabular}


R\&D Program Area: Automated Diagnostics, PM, Comm. \& Optimal Control Tools

R\&D Project Activity: Commissioning

Team members:

Completed by: Jeff Schein

\begin{tabular}{|c|l|l|}
\hline Years & \multicolumn{1}{|c|}{ Activities } & \multicolumn{1}{c|}{ Outcomes } \\
\hline $1-2$ & Field-based case studies & $\begin{array}{l}\text { Petermine costs and benefits of crosscutting, } \\
\text { eespecially for new buildings. } \\
\text { Develop problems for standardized } \\
\text { facility tests. }\end{array}$ \\
\hline $3-5$ & $\begin{array}{l}\text { Develop methods for energy-oriented cross- } \\
\text { cutting. }\end{array}$ & $\begin{array}{l}\text { Majority of existing test methods address fault } \\
\text { of controls and HVAC systems. The } \\
\text { proposed work will develop additional tests } \\
\text { that address the interaction between systems } \\
\text { to help evaluate energy performance of } \\
\text { buildings. }\end{array}$ \\
\hline $5-10$ & Environment (re)-discovery & $\begin{array}{l}\text { "Plug and Play" nodes on building control } \\
\text { networks. }\end{array}$ \\
& & $\begin{array}{l}\text { As building layout changes, nodes adapt. } \\
\text { Includes knowledge of other nodes, i.e., where } \\
\text { to directly change requirements. }\end{array}$ \\
\hline
\end{tabular}


R\&D Program Area: Automated Diagnostics, PM, Comm. \& Optimal Control Tools R\&D Project Activity: Tools

Team members:

Completed by:

\begin{tabular}{|c|c|c|c|}
\hline Years & Activities & Outcomes & Partners \\
\hline $1-2$ & $\begin{array}{l}\text { Simulation programs that model building } \\
\text { energy systems and their interactions (HVAC, } \\
\text { lighting, on-site generation ...) for crosscutting } \\
\text { support. } \\
\text { Tools for active crosscutting tests } \\
\text { Controls simulations } \\
\text { - R\&D for control strategies and FDD } \\
\text { - Design } \\
\text { - Education and training } \\
\text { Models } \\
\text { Interfaces } \\
\text { National web-based access of controls } \\
\text { simulation tools }\end{array}$ & & \\
\hline $3-5$ & Work continues & & \\
\hline $5-10$ & Work continues & & \\
\hline
\end{tabular}


R\&D Program Area: Automated Diagnostics, PM, Comm. \& Optimal Control Tools

R\&D Project Activity: Market Characterization

Team members: Sensors and Controls Breakout Group

Completed by: Michael Brambley

\begin{tabular}{|c|c|c|c|}
\hline Years & Activities & Outcomes & Partners \\
\hline $1-2$ & $\begin{array}{l}\text { - Human “dimensions” research } \\
\text { - } \quad \text { Identify more detailed stakeholder needs. } \\
\text { - Establish consortia with partnerships } \\
\quad \text { especially owner/manager/operator. } \\
\text { Building segmentation system (e.g., } \\
\text { large/built-up and small/packaged) }\end{array}$ & $\begin{array}{l}\text { Answer Question: } \\
\text { - "What do people really want?" } \\
\text { - Need to know for each key stakeholder } \\
\text { and constituency in the building life } \\
\text { cycle. } \\
\text { Need to develop solutions that match } \\
\text { business models. }\end{array}$ & \\
\hline $3-5$ & $\begin{array}{l}\text { Link product development life cycle with } \\
\text { building life cycle when considering product } \\
\text { R\&D } \\
\text { • More value in tools developed } \\
\text { collaboratively with product developers, } \\
\text { researchers, and building industry } \\
\text { representatives. }\end{array}$ & Products enter the marketplace. & \\
\hline $5-10$ & $\begin{array}{l}\text { Look for value-added (e.g., disaster } \\
\text { mitigation) to combine R\&D funding } \\
\text { resources. }\end{array}$ & & \\
\hline
\end{tabular}




\section{Distribution}

No. of

\section{Copies}

\section{OFFSITE}

Don Anderson

ICF Consulting Inc

9300 Lee Highway

Fairfax, VA 22301

Karen Benedek

TIAX, LLC

15 Acorn Park

Cambridge, MA 02140-2328

David Bornside

Siemens Building Technologies

1000 Deerfield Parkway

Buffalo Grove, IL 60089

Joseph Borowiec

NYSERDA

Building R\&D

17 Columbia Circle

Albany, NY 12203

Martha Brook

California Energy Commission

MS-42

1516 Ninth Street

Sacramento, CA 95814

Karl Brown

California Institute for Energy Efficiency

1333 Broadway Suite 240

Oakland, CA 94612

Steven Bushby

NIST

Building Environment Division (863)

100 Bureau Drive, Stop 8631

Gaithersburg, MD 20899-8631

Ronald Caffrey

BCS Partners

2008 Carolina Circle N.E.

St. Petersburg, FL 33703
Michael Chapman

Naval Facilities Engineering Command

Design Policy/Architecture

1322 Patterson Avenue, SE

Washington Navy Yard

Washington, DC 20374-5065

David Claridge

Texas A\&M University

Department of Mechanical Engineering

College Station, TX 77843-3123

Dru Crawley

U.S. Department of Energy

1000 Indepedence Ave, SW, EE-2J

Washington, DC 20585

Paul Ewing

RF \& Microwave Systems Group

Oak Ridge National Laboratory

One Bethel Valley Road

Building 3500 MS 6006 Room B18

PO Box 2008

Oak Ridge, TN 37831-6006

Kevin Finnegan

Battery Park City Authority

One World Financial Center

New York, NY 10281-1097

Theo Frutiger

Siemens Building Technologies

Siemens SBT HVAC Products

1000 Deerfield Parkway

Buffalo Grove, IL 60089

Vijay Gupta

U.S. General Services Administration

Office of the Chief Architect

1800 F Street, NW

Washington, DC 20405

20 David Hansen

U.S. Department of Energy

1000 Independence Ave, SW, EE-2J

Washington, DC 20585

Tom Hartman

The Hartman Company

9905 39th Drive NE

Marysville, WA 98270

Distr. 1 
Philip Haves

Lawrence Berkeley National Laboratory

Building 90, MS 90-3074

1 Cyclotron Road

Berkeley, CA 94720

5

David Holmberg

NIST

Building Environment Division (863)

100 Bureau Drive, Stop 8631

Gaithersburg, MD 20899-8631

John House

Iowa Energy Center

Suite 124

2521 Elwood Drive

Ames, Iowa 50010-8263

Steve Karg

Lithonia Lighting

One Lithonia Way

Building 1

Decatur, GA 30035

Roger Kisner

Oak Ridge National Laboratory

One Bethel Valley Road

Building 37831 MS 6004

P.O. Box 2008

Oak Ridge, TN 37831-6004

Ron Lewis

U.S. Department of Energy

1000 Independence Ave, SW, EE-2J

Washington, DC 20585

Eric Lightner

U.S. Department of Energy

Office of Electric Transmission and

Distribution

1000 Independence Ave, SW, EE-2D

Washington, DC 20585

Vivian Loftness

Carnegie Mellon University

Architecture Department

Head of the School of Architecture

500 Forbes Avenue

4919 Frew St. Room 201

Pittsburgh, PA 15213

Tom Lohner

Teng \& Associates

4050 Innslake Drive

Suite 300

Glen Allen, VA 23060-3327

John McKissack

The Kele Companies

3300 Brother Boulevard

Memphis, TN 38133

Terrence McMahon

BCS Partners

135 Fort Lee Road

Leonia, NY 07605

Mark Myers

United Technologies Research Center

411 Silver Lane

Mail Stop 129-85

East Hartford, CT 06108

$5 \quad$ Kurt Roth

TIAX, LLC

15 Acorn Park

Cambridge, MA 02140-2328

John Ryan

U.S. Department of Energy

1000 Independence Ave, SW, EE-2J

Washington, DC 20585

Harvey Sachs

ACEEE

Buildings Programs

1001 Connecticut Ave NW, Suite 801

Washington, DC 20036

Michael K. Sahm

United Technologies Research Center

411 Silver Lane

Mail Stop 129-65

East Hartford, CT 06108

Jeffrey Schein

NIST

Building Environment Division (863)

100 Bureau Drive, Stop 8631

Gaithersburg, MD 20899-8631

John Seem

Johnson Controls

507 East Michigan Street

Mail Stop M36

Milwaulkee, WI 53202

Sandy Smith

ACEEE

Buildings Programs

1001 Connecticut Ave NW, Suite 801

Washington, DC 20036

Distr. 2 
Mike Stein

Mike Stein Associates

40 Alize Drive

Kinnelon, NJ 07504

Randal Stites

Hines GS Properties, Inc.

901 D. Street, SW

Box 18, Suite 290

Washington, DC 20024-2169

$5 \quad$ Paul Torcellini

National Renewable Energy Laboratory

1617 Cole Blvd

Mail Stop 2722

Golden, CO 80401-3393

Stephen Treado

NIST

Building Environment Division (863)

1000 Bureau Drive, Stop 8631

Gaithersburg, MD 20899-8631

Martin Weiland

ASHRAE

1828 L St. N.W., Suite 906

Washington, DC 20036-5104

Robert Williams

Continental Automated Buildings Association

(CABA)

4200 NW 74th Court

P.O. Box 901525

Kansas City, MO 64151
No. of

Copies

\section{ONSITE}

\section{Pacific Northwest National Laboratory}

Michael Brambley (5)

K5-16

Sean McDonald (20)

BWO

Marylyn Placet

BWO

Theresa Gilbride

BPO

Information Release Office (2)

Distr. 3 
PNNL-15148

Distr. 4 